\title{
Imagem Cognitiva e Imagem Afetiva: um estudo do destino Blumenau, SC, Brasil
}

\author{
Jessica Vieira de Souza Meiraa \\ Fabrícia Durieux Zuccob \\ Thiago dos Santos ${ }^{c}$
}

\section{Resumo}

Nos últimos anos, observou-se um aumento considerável de destinos que almejam desenvolver a atividade turística com o objetivo de alavancar a economia local. Concomitante a esta situação, surgiram estudos voltados à competitividade de destinos, englobando as mais diversas temáticas, voltadas principalmente ao marketing e à gestão. A imagem de destinos é abordada com bastante frequência nesses estudos, uma vez que, por meio dela, um destino pode diferenciar-se de seus concorrentes. Em virtude desse cenário, este estudo tem como objetivo realizar uma análise comparativa entre a imagem cognitiva e a imagem afetiva do destino Blumenau (SC, Brasil). A pesquisa caracteriza-se por ser exploratória, descritiva e comparativa, com abordagem qualiquantitativa. Para descrever a imagem cognitiva, realizou-se uma análise morfológica e de conteúdo das 579 palavras e 117 imagens encontradas nos folders e no site promocional da cidade. Posteriormente, aplicou-se aos dados a Modelagem de Equação Estrutural (MEE) e testes de correlação (Coeficiente de Spearman). Para descrever a imagem afetiva, utilizou-se o estudo realizado por Reis et al., que analisa a marca Blumenau a partir da perspectiva dos seus residentes. Os resultados demonstram que a imagem cognitiva corresponde à afetiva, uma vez que a comunicação publicitária de Blumenau promove a cultura germânica, elemento fundamental da autoimagem dos residentes do município.

Palavras-chave: Imagem cognitiva; Imagem afetiva; Destino turístico; Blumenau (SC, Brasil).

\section{Abstract \\ Cognitive and affective image: a study of Blumenau, Santa Catarina, Brazil, as a tourism destination}

In recent years, we have been observed a considerable increase of tourism destinations that aim to develop tourism with the goal of improving local economies. At the same time, new studies have emerged focusing on the competitiveness of these touristic places, addressing the most diverse topics - mainly related to marketing and management. The image of tourism destinations is quite often discussed in these studies, since one can use it to compare touristic cities. Considering this context, this study aims to carry out

a. Doutoranda em Turismo e Hotelaria pela Universidade do Vale do Itajaí (Univali). Mestre em Turismo e Hotelaria. Balneário Camboriú, Santa Catarina, Brasil. E-mail: jessica.meira@edu.univali.br

b. Doutora em Administração pela Universidade Nove de Julho (Uninove). Professora Titular na Univali e na Fundação Universidade Regional de Blumenau (Furb). Blumenau, Santa Catarina, Brasil. E-mail: fabriciazucco@hotmail.com

c. Mestre em Administração pela Univali. Professor na Furb e Coordenador do Centro Técnico de Blumenau (CEDUPHH) em Marketing, Pesquisa de Mercado, Administração de Serviços, Comportamento do Consumidor e Publicidade e Propaganda. Blumenau, Santa Catarina, Brasil. E-mail: santosthiago07@gmail.com 
a comparative analysis between the cognitive and affective image of Blumenau, Santa Catarina, Brazil. The research is exploratory, descriptive and comparative, with qualiquantitative approach. To describe the cognitive image, we conducted a morphological and content analysis of 579 words and 117 images from tourism folders and an analysis of the city website. After this, we used Structural Equation Modeling (SEM) and correlation tests (Spearman's coefficient) to analyze the data. To describe the affective image, we used the study conducted by Reis et al. in which the researchers analyzed the Blumenau branding from the perspective of its residents. The results show that the cognitive image corresponds to the affective image, since the advertising of Blumenau promotes the German culture, an essential element for the residents' self-image.

Keywords: Cognitive image; Affective image; Tourism destination; Blumenau (Santa Catarina, Brazil).

\section{Resumen}

\section{Imagen afectiva e imagen cognitiva: un estudio de lo destino Blumenau, SC, Brasil}

En los últimos años, se observó un aumento considerable de destinos que anhelan desarrollar el turismo con el objetivo de impulsar la economía local. Concomitante a esta situación, empezaron a surgir estudios centrados en la competitividad de los destinos, englobando las más diversas temáticas, pero sobretodo el marketing y la gestión La imagen de destinos se discute con bastante frecuencia en estos estudios, ya que, a través de ella, un destino puede diferenciarse de sus competidores. Bajo este escenario, este estudio tiene como objetivo realizar un análisis comparativo de las imágenes cognitiva y afectiva del destino Blumenau (SC, Brasil). La investigación se caracteriza como exploratoria, descriptiva y comparativa, con abordaje cualicuantitativo. Para describir la imagen cognitiva, se realizó un análisis morfológico y de contenido de 579 palabras y 117 imágenes de folletos promocionales y del sitio web de divulgación de la ciudad. Posteriormente, se aplicó a los datos el Modelo de Ecuaciones Estructurales (MEE) y pruebas de correlación (Coeficiente de Spearman). Para describir la imagen afectiva, se utilizó el estudio de Reis et al., que analiza la marca Blumenau desde la perspectiva de sus residentes. Los resultados demuestran que la imagen cognitiva corresponde a la imagen afectiva, ya que la comunicación publicitaria de Blumenau promueve la cultura alemana, un elemento clave en la autoimagen de los residentes del municipio.

Palabras clave: Imagen cognitiva; Imagen afectiva; Destino turístico; Blumenau (SC, Brasil).

\section{CONTEXTUALIZAÇÃo}

Atualmente, com o objetivo de alavancarem-se economicamente, muitos destinos estão procurando o desenvolvimento da atividade turística. Nesse processo, deparam-se com um cenário altamente competitivo, onde o fator diferenciação possui importância fundamental para a sobrevivência no mercado (BASAN; BAGARIC; LOCARIC, 2013; CHAGAS, 2008; UPADHYAYA, 2012). Em decorrência do aumento da competitividade, diversos estudos vêm sendo desenvolvidos, abordando, principalmente, as temáticas de marketing e gestão. A imagem das destinações turísticas vem sendo assunto frequente de discussões, visto que a literatura do turismo apresenta os destinos como marcas corporativas, que podem ser promovidas no mercado e comunicadas aos públicos interessados (CHAGAS, 2008; KARABAG; YAVUZ; BERGGREN, 2011). 
A gestão da imagem do destino turístico deve ser realizada de maneira que a sua singularidade seja enfatizada, uma vez que ela exerce influência significativa no posicionamento estratégico do destino, aumentando a sua atratividade e, com isso, tornando-o mais competitivo no mercado (BERTOLI, 2014; CHAGAS, 2008; MERRILEES; MILLER; HERINGTON, 2008; PEREIRA, 2013; PIKE, 2007). Por isso, é preciso investir em atividades que envolvam o planejamento da criação de uma imagem com características diferenciadoras que visam atender as necessidades dos residentes, visitantes e demais públicos potenciais (BASAN; BAGARIC; LONCARIC, 2013; REIS et al., 2015). Afinal, uma imagem promovida de forma correta e eficaz é considerada uma maneira de se obter vantagem competitiva a longo prazo (GIACOMINI FILHO, 1998; MERRILEES; MILLER; HERINGTON, 2008).

A imagem que o destino transmite afeta a percepção dos indivíduos e influencia o comportamento de compra do turista, principalmente em relação à escolha e possível repetição do destino (CHAGAS, 2008; PEREIRA, 2013). Identificar a imagem que caracteriza o destino através da valorização de suas características distintivas, como tradição, história e cultura, auxilia o seu posicionamento no mercado (BERTOLI, 2014; CHAGAS, 2008; PEREIRA, 2013; PÉREZ-NEBRA; TORRES, 2002). 0 processo de criação da imagem de uma cidade turística é uma das principais funções da gestão do marketing de destinos, que também se responsabiliza pela comunicação dessa imagem para os seus públicos (BERTOLI, 2014). 0 objetivo desse processo é transmitir uma identidade única e competitiva dentro da mente do consumidor (STANCIOIU et al., 2011).

Segundo os estudos de Merrilees, Miller e Herington (2008) e Upadhyaya (2012), a temática imagem de destinos é ainda recente na investigação acadêmica e conta com poucos trabalhos publicados. Em virtude desse cenário, a presente investigação objetiva realizar uma análise comparativa entre a imagem cognitiva e a imagem afetiva do destino Blumenau (SC). Optou-se por esse destino em virtude do estudo de Reis et al. (2015), que, ao pesquisar o city branding na perspectiva dos moradores de Blumenau, identificou a imagem afetiva ligada ao município. A imagem cognitiva, por sua vez, será identificada por meio das palavras e imagens existentes nos materiais promocionais da cidade. Esta investigação busca analisar se o destino turístico vende sua personalidade desenvolvida com base em seus aspectos diferenciadores.

\section{IMAGEM DE DESTINO}

Muitos autores acreditam que a imagem proporcionada pelos destinos exerce influência no processo de escolha de determinada destinação turística (ACERENZA, 2002; BERTOLI, 2014; CHAGAS, 2008; LI, 2012; PIKE, 2007; UPADAHYAYA, 2012). Por isso, muitos municípios estão focando os seus esforços de marketing na publicidade da imagem como fator de competitividade (GIACOMINI FILHO, 1998). 0 grande desafio enfrentado pelos destinos, porém, é identificar a imagem que melhor retrate a sua personalidade, isto é, seus aspectos peculiares, diferenciadores, capazes de atrair um maior número de turistas (BERTOLI, 2014; PEREIRA, 2013; REIS et al., 2015; UPADAHYAYA, 2012).

Conceituar o termo "imagem de destinos" é algo complexo. Neste estudo, será adotada a definição proposta pelas investigações de Acerenza (2002), Chagas (2008), Chagas e Marques Júnior (2011) e Stancioiu et al. (2011), que consideram 
"imagem de destino" a representação mental associada a uma determinada destinação. A criação dessa imagem, que determina a personalidade do destino por meio de um valor simbólico baseado em conhecimento e focado nas emoções que o local pretende causar em seus diversos públicos, é de fundamental importância para o desenvolvimento turístico (BERTOLI, 2014; PEREIRA, 2013; REIS et al., 2015; STANCIOIU et al., 2011).

Alguns gestores utilizam os seus produtos turísticos, principalmente os grandes festivais e as características culturais diferenciadoras, com o objetivo de promover a cidade como marca corporativa (KARABAG; YAVUZ; BERGGREN, 2011). De acordo com estudos como o realizado por Basan, Bagaric e Loncaric (2013), um destino com uma marca forte e reconhecida pelos seus diversos públicos tem melhor imagem no mercado. Dessa forma, utilizar os atrativos turísticos como componentes do processo de posicionamento da marca é de importância fundamental para o posicionamento estratégico do destino turístico (LUBOWIECKI-VIKUK; BASINSKA-ZYCH, 2011).

Nos últimos anos, houve um aumento de discussões a respeito da temática imagem de destinos. Os autores Pike e Scott (2009) realizaram um estudo na Austrália para examinar o envolvimento dos residentes com a marca, verificando a congruência entre a imagem projetada e a identidade do destino. Concluíram que $o$ acolhimento da comunidade representa uma forte ferramenta de vantagem competitiva. No Brasil, em Natal (RN), Chagas e Marques Júnior (2011) analisaram a relação entre a qualidade, satisfação, fidelidade e imagem de destinos. Os autores concluíram que a imagem complexa, ou seja, originada após a experimentação do produto, influencia diretamente na qualidade, satisfação e fidelidade.

Os autores Achterkamp, Robinson e Moital (2011) analisaram a imagem da Alemanha como destino de férias, encontrando como pontos fortes os passeios turísticos, limpeza e acessibilidade; como pontos negativos, o clima, as praias e os preços. Esse estudo concluiu que o material promocional não exerce influência na decisão de visitar a Alemanha, talvez pela ausência ou até mesmo pela ineficácia das informações.

Já no estudo de Mendes, Valle e Guerreiro (2011), foram exploradas a relação entre a imagem projetada e a imagem, como destino turístico, da região de Algarve, em Portugal. Os autores concluíram que os elementos afetivos não são percebidos pelos turistas.

Outro autor que também utilizou destinos portugueses como objeto de estudo foi Tojal (2014), que discutiu em sua pesquisa a importância que as representações estereotipadas dos destinos e de seus habitantes assumem nos textos dos folhetos e brochuras promocionais. Após análise de três cidades do litoral norte de Portugal, o autor concluiu que essas representações exercem influência no processo de escolha do destino turístico.

Explorar e avaliar a estrutura dos componentes cognitivos da imagem do destino turístico de sol e mar na Grécia foi o objetivo de Stylos e Andronikidis (2013). Os autores discutiram a respeito dos fatores que afetam a formação da imagem, sugerindo quatro dimensões.

O objetivo do estudo de Limberger, Anjos e Pereira (2013) foi analisar a efetividade da comunicação do destino de Balneário Camboriú (SC) com base na percepção de seus turistas e de seus gestores públicos e privados. Os autores concluíram que, embora a mensagem induzida seja condizente com os serviços turísticos oferecidos, ainda é preciso aprimorá-la. 
O estudo de Buosi e Silva (2013) buscou relacionar a imagem percebida e a avaliação global feita por 280 turistas que visitaram o município de Jericoacoara (CE) durante o período da pesquisa. Os resultados apontam a relevância dos atributos da imagem para a avaliação global satisfatória do destino.

Na base de dados de periódicos científicos Elton Bryson Stephens Company foram encontrados 286 artigos que abordaram a temática imagem do destino. Foi utilizada a palavra-chave "destination image" com a delimitação temporal entre os anos de 2005 e 2015. A maioria dos artigos foram provenientes da China (29), Turquia (11) e Taiwan (10), e, das cinquenta revistas encontradas, as que se destacaram com um maior número de publicações foram a International Journal of Tourism Research, com 35 artigos, e a Tourism Tribune, com 23 artigos. 0 Quadro 1 apresenta os artigos encontrados na base de dados Ebsco.

Quadro 1 - Principais estudos voltados à temática destination image dos últimos anos

\begin{tabular}{|l|l|}
\hline Termo do Thesaurus & Autores \\
& Pike e Scott (2009) \\
& Achterkamp, Robinson e Moital (2011) \\
Mendes, Valle e Guerreiro (2011) \\
Atrações Turísticas & Limberger, Anjos e Pereira (2013) \\
& Tojal (2014) \\
\hline Imagem de Destino & Pike (2007) \\
& Achterkamp, Robinson e Moital (2011) \\
& Chagas e Marques Junior (2011) \\
& Lyu, Xu e Lin (2014) \\
\hline Marketing de Lugar & Pike e Scott (2009) \\
& Buosi e Silva (2013) \\
Lyu, Xu e Lin (2014)
\end{tabular}

Esta investigação irá comparar a imagem cognitiva e a imagem afetiva do destino Blumenau. Segundo Gartner (1993), a imagem cognitiva pode ser considerada como o conhecimento dos componentes racionais baseados nos atributos mensuráveis do destino, enquanto a imagem afetiva é baseada em valores individuais formados pela relação com determinado destino e os sentimentos por ela despertados.

\section{CITY BRANDING}

O termo "city branding" pode ser definido como um conjunto de atividades destinadas à criação de uma imagem exclusiva de um determinado lugar, a fim de identificar, formular e divulgar suas características particulares na disputa com outras cidades (REIS et al., 2015). A otimização do posicionamento da marca aumenta a competitividade do destino, gerando mais oportunidades e mantendo a sua vitalidade. Projetar e promover um local de modo que seja atrativo para os residentes e visitantes, satisfazendo as necessidades de todos, 
é o objetivo principal dos destinos que visam gerar uma imagem de marca positiva (KARABAG; YAVUZ; BERGGREN, 2011; REIS et al., 2015).

0 estudo realizado por Stancioiu et al. (2011) teve como objetivo destacar o papel que a imagem do destino desempenha no desenvolvimento da marca e identificar os principais atrativos turísticos das regiões históricas da Romênia. Os autores concluíram que a imagem identificada pelos habitantes como sendo a marca do destino está relacionada com a paisagem natural.

Já os autores Karabag, Yavuz e Berggren (2011) examinaram a relação entre os festivais da Turquia e da Suécia e a promoção e comunicação das cidades em diferentes níveis de mercado. Os autores concluíram que, apesar de sua importância para os moradores, os festivais apresentam temas genéricos e são pouco promovidos.

Discutir a importância da criação de uma marca de destino nacional, regional e local para a Polônia é o objetivo da investigação realizada por Lubowiecki-Vikuk e Basinska-Zych (2011). Os autores concluíram que o esporte e o turismo são importantes componentes do processo de posicionamento de marca.

Um estudo realizado na Índia, por Upadhyaya (2012), teve como objetivo desenvolver uma compreensão sobre os principais fatores que contribuem para identificar os traços de personalidade na imagem de destino. 0 autor confirmou sua hipótese empiricamente, por meio de seis dimensões relacionadas à personalidade e cinco dimensões relacionadas à imagem do destino.

Foram encontrados treze artigos com as palavras-chave "city branding" ou city brand na base de dados de periódicos científicos internacionais Ebsco. A delimitação temporal utilizada corresponde ao período entre os anos de 2005 e 2015. A maioria dos artigos foi proveniente de cidades europeias (oito artigos), dois deles da Turquia. Os artigos estão distribuídos entre onze revistas científicas, com três investigações publicadas pela Tourism Tribune.

Quadro 2 - Principais estudos voltados à temática city branding dos últimos anos

\begin{tabular}{|c|c|}
\hline Termo do Thesaurus & Autores \\
\hline Competitividade & $\begin{array}{l}\text { Upadhyaya (2012) } \\
\text { Xu et al. (2013) }\end{array}$ \\
\hline Cultura e Turismo & Zhou e Su (2014) \\
\hline Destinos & $\begin{array}{l}\text { Domenico e Domenico (2007) } \\
\text { Stancioiu, Teodorescu, Pargaru, Vladoi e Baltescu (2011) } \\
\text { Upadhyaya (2012) } \\
\text { Xu, Qin, Zhang, Qi e Li (2013) }\end{array}$ \\
\hline Festivais & Karabag, Yavuz e Berggren (2011) \\
\hline Herança Cultural & Domenico e Domenico (2007) \\
\hline Imagem da Marca & $\begin{array}{l}\text { Lubowiecki-Vikuk e Basinka-Zych (2011) } \\
\text { Stancioiu, Teodorescu, Pargaru, Vladoi e Baltescu (2011) } \\
\text { Upadhyaya (2012) }\end{array}$ \\
\hline Marketing de Lugar & Lubowiecki-Vikuk e Basinka-Zych (2011) \\
\hline Marketing Turístico & $\begin{array}{l}\text { Karabag, Yavuz e Berggren (2011) } \\
\text { Wang e Li (2012) }\end{array}$ \\
\hline Promoção de Destinos & Karabag, Yavuz e Berggren (2011) \\
\hline
\end{tabular}


No Brasil, o estudo realizado por Bertoli (2014) teve como objetivo identificar a representação de Blumenau nas redes sociais de fotografia, analisando as implicações dessa representação para a imagem de destino da cidade. 0 estudo de Donaire e Galí (2011) realizado em Barcelona serviu para o autor como base para delimitar as dimensões a serem estudadas. Os resultados mais expressivos estavam relacionados a aspectos gerais, lazer, gastronomia, elementos urbanos e arquitetura típica.

A investigação de Reis et al. (2015) - que, neste estudo, será utilizada para a identificação da imagem afetiva do destino estudado - teve como objetivo analisar os atributos da marca Blumenau a partir da perspectiva de seus residentes. Por meio de técnicas estatísticas, o trabalho estudou a relação entre as características do município e a avaliação global feita por seus moradores. As dimensões analisadas foram baseadas no estudo de Merrilees, Miller e Herington (2008) realizado na Austrália.

\section{PROCEDIMENTOS METODOLÓGICOS}

Esta investigação, de abordagem qualiquantitativa, caracteriza-se por ser exploratória, descritiva e comparativa, realizada por meio da análise cruzada entre a perspectiva dos residentes com relação à marca Blumenau e o material promocional distribuído pelo município. Para a descrição da imagem afetiva (relacionada à percepção dos residentes), serão utilizados os resultados apresentados no estudo de Reis et al. (2015). Para descrever a imagem cognitiva, serão analisadas estatisticamente 579 palavras (substantivos e adjetivos) e 117 imagens encontradas no site da Secretaria de Turismo de Blumenau e nos onze folders promocionais distribuídos no ano de 2015 (Tabela 1).

Tabela 1 - Material promocional analisado

\begin{tabular}{|l|c|c|}
\hline Material promocional & Palavras & Imagens \\
\hline Sommerfest 2015 & 59 & 06 \\
\hline Miss Blumenau 2015 & 08 & 01 \\
\hline Festival da Cerveja 2015 & 57 & 05 \\
\hline Osterdorf 2015 & 49 & 07 \\
\hline Cãominhada 2015 & 14 & 01 \\
\hline Caminhada das Nascentes 2015 & 19 & 07 \\
\hline Torneio de Canastra 2015 & 51 & 02 \\
\hline Festitália 2015 & 11 & 04 \\
\hline Oktoberfest 2015 & 93 & 08 \\
\hline Blumenau Festas e Eventos & 103 & 14 \\
\hline Parque Vila Germânica & 62 & 28 \\
\hline Site da Secretaria de Turismo & 53 & 34 \\
\hline TOTAL & Fonte - Elaborado pelos autores & $\mathbf{1 1 7}$ \\
\hline
\end{tabular}

As palavras e imagens foram classificadas em cinco dimensões, baseadas nos estudos de Donaire e Galí (2011): arquitetura típica, eventos, gastronomia, iden- 
tidade típica e lazer (turismo). Os próprios autores, separadamente, realizaram a classificação das palavras e imagens. Em um segundo momento, foi realizada uma reunião para a junção das percepções com relação às cinco dimensões. Somente em um terceiro momento, realizou-se a distribuição final das palavras e imagens nas dimensões consideradas mais apropriadas. Com o intuito de categorizar da forma mais coerente possível o material, selecionou-se a característica mais marcante de cada uma das imagens, perceptível à primeira impressão.

Os onze folders promocionais - nove de eventos diversos (Sommerfest, Miss Blumenau, Festival da Cerveja, Osterdorf, Cãominhada, Caminhada das Nascentes, Torneio de Canastra, Festitália e Oktoberfest) e dois guias (Blumenau Festas e Eventos e Parque Vila Germânica) - foram disponibilizados por um funcionário da Secretaria de Turismo da cidade de Blumenau. 0 site utilizado no estudo (www. blumenau.sc.gov.br/secretarias/secretaria-de-turismo) foi visualizado nos dias 15 de setembro de 2015 e 30 de setembro de 2015, sendo importante destacar que as palavras e imagens analisadas foram extraídas da página principal do website.

Após a distribuição das palavras e imagens nas cinco dimensões citadas anteriormente, foram criadas planilhas no Microsoft Excel com o objetivo de escolher o melhor tratamento estatístico a ser empregado. ${ }^{1}$ Optou-se, então, pela Modelagem de Equação Estrutural (MEE), que, segundo Reis et al. (2015), permite visualizar graficamente, por meio do Coeficiente de Spearman, testes de correlação; e, por meio do diagrama de caminhos, a relação entre as dimensões de estudo. Com base nesses dados, propôs-se a seguinte hipótese, a ser aceita ou rejeitada:

- H1: Existe uma relação positiva entre o material promocional e a autoimagem dos residentes na cidade de Blumenau.

\section{ANÁLISE E DISCUSSÃo DOS RESULTADOS}

Blumenau está localizada no sul do Brasil, no centro-norte do estado de Santa Catarina, na região conhecida como Vale do Itajaí. 0 município, que foi fundado em 1850 por imigrantes alemães, guarda fortes características europeias, sendo considerado uma das cidades brasileiras com maior influência germânica em sua cultura, história, arquitetura e gastronomia (BLUMENAU, 2015; REIS et al., 2015). Com $510 \mathrm{~km}^{2}$ de extensão e quase 330.000 habitantes, é a terceira maior e mais populosa cidade catarinense. Sua maior atividade econômica é a indústria têxtil, responsável por aproximadamente 70\% da arrecadação do município (BLUMENAU, 2015).

Os resultados alcançados por esta investigação serão apresentados a seguir, de forma sequencial. Primeiramente, serão apresentados os resultados alcançados por meio da análise das palavras e imagens identificadas nos materiais promocionais da cidade (fonte primária). Em um segundo momento, serão descritos os resultados alcançados no estudo de Reis et al. (2015) relacionados à percepção dos moradores de Blumenau com relação à imagem identificada como marca da cidade (fonte secundária). Por último, será realizada uma discussão com o objetivo de cotejar os resultados obtidos em cada etapa da análise. Nesse momento, serão comparadas as imagens cognitiva e afetiva do destino Blumenau.

1. Para o trabalho estatístico, foi utilizado o programa Statistical Package for the Social Sciences (SPSS) versão 21.0. 


\section{Imagem cognitiva $x$ Imagem afetiva}

Para identificar a imagem cognitiva do destino Blumenau, realizou-se uma análise morfológica das 579 palavras encontradas nos onze folders promocionais distribuídos no ano de 2015 e publicados no site da Secretaria de Turismo. Por meio da análise das palavras, foi possível verificar uma maior incidência na categoria eventos, com 219 citações, e gastronomia, com 107. A categoria arquitetura típica, com 59 menções, foi a menos citada.

Na Tabela 2, é possível visualizar a distribuição das palavras dos materiais promocionais entre as cinco categorias definidas pela investigação.

Tabela 2 - Distribuição das palavras encontradas nos materiais promocionais

\begin{tabular}{|c|c|c|c|c|c|c|}
\hline $\begin{array}{l}\text { Material } \\
\text { Promocional / } \\
\text { Categorias }\end{array}$ & $\begin{array}{l}\text { Arquitetura } \\
\text { Típica }\end{array}$ & Eventos & Gastronomia & $\begin{array}{c}\text { Identidade } \\
\text { Típica }\end{array}$ & $\begin{array}{c}\text { Lazer } \\
\text { (Turismo) }\end{array}$ & Total \\
\hline Sommerfest & 08 & 10 & 13 & 14 & 14 & 59 \\
\hline Miss Blumenau & 03 & 05 & 00 & 00 & 00 & 08 \\
\hline $\begin{array}{l}\text { Festival da } \\
\text { Cerveja }\end{array}$ & 04 & 13 & 33 & 02 & 05 & 57 \\
\hline Osterdorf & 08 & 29 & 02 & 05 & 05 & 49 \\
\hline Cãominhada & 03 & 11 & 00 & 00 & 00 & 14 \\
\hline $\begin{array}{l}\text { Caminhada das } \\
\text { Nascentes }\end{array}$ & 01 & 10 & 00 & 00 & 08 & 19 \\
\hline $\begin{array}{l}\text { Torneio de } \\
\text { Canastra }\end{array}$ & 06 & 43 & 00 & 00 & 02 & 51 \\
\hline Festitália & 02 & 04 & 01 & 02 & 02 & 11 \\
\hline Oktoberfest & 08 & 35 & 16 & 23 & 11 & 93 \\
\hline $\begin{array}{l}\text { Blumenau } \\
\text { Festas e Eventos }\end{array}$ & 09 & 42 & 18 & 27 & 07 & 103 \\
\hline $\begin{array}{l}\text { Parque Vila } \\
\text { Germânica }\end{array}$ & 07 & 11 & 16 & 06 & 22 & 62 \\
\hline $\begin{array}{l}\text { Secretaria de } \\
\text { Turismo }\end{array}$ & 00 & 06 & 08 & 19 & 20 & 53 \\
\hline TOTAL GERAL & 59 & 219 & 107 & 98 & 96 & 579 \\
\hline
\end{tabular}

Fonte - Elaborado pelos autores

A categoria eventos foi a mais citada em oito dos doze materiais promocionais, destacando-se, principalmente, nos folders da Osterdorf (29), Torneio de Canastra (43), Oktoberfest (35) e Blumenau Festas e Eventos (42). Quanto à categoria gastronomia, pode-se destacar os folders do Festival da Cerveja (33) e do Parque Vila Germânica (16). Na categoria identidade típica, pode-se destacar os folders da Sommerfest (14), Oktoberfest (23) e Blumenau Festas e Eventos (27). A categoria lazer foi a mais citada nos folders da Sommerfest (14) e do Parque Vila Germânica (22). No site da Secretaria de Turismo as categorias mais citadas foram identidade típica (19) e lazer (20). A categoria arquitetura típica foi a menos citada nos folders da Sommerfest (8) e Oktoberfest (8); no site da Secretaria de Turismo, não foi citada. 
Com a análise conteúdo das 117 imagens encontradas nos onze folders promocionais e no site da Secretaria de Turismo de Blumenau, foi possível verificar que as categorias mais representativas foram identidade típica, com 35 imagens, e eventos, com 25. A categoria lazer foi a que menos incidiu nas imagens encontradas nos materiais, com apenas dezoito aparições. Na Tabela 3, é possível visualizar a distribuição das imagens entre as cinco categorias definidas pela investigação.

Tabela 3 - Distribuição das imagens encontradas nos materiais promocionais

\begin{tabular}{|c|c|c|c|c|c|c|}
\hline $\begin{array}{l}\text { Material } \\
\text { Promocional / } \\
\text { Categorias }\end{array}$ & $\begin{array}{l}\text { Arquitetura } \\
\text { Típica }\end{array}$ & Eventos & Gastronomia & $\begin{array}{c}\text { Identidade } \\
\text { Típica }\end{array}$ & $\begin{array}{c}\text { Lazer } \\
\text { (Turismo) }\end{array}$ & Total \\
\hline Sommerfest & 03 & 00 & 00 & 03 & 00 & 06 \\
\hline Miss Blumenau & 00 & 01 & 00 & 00 & 00 & 01 \\
\hline $\begin{array}{l}\text { Festival da } \\
\text { Cerveja }\end{array}$ & 00 & 00 & 05 & 00 & 00 & 05 \\
\hline Osterdorf & 01 & 06 & 00 & 00 & 00 & 07 \\
\hline Cãominhada & 00 & 00 & 00 & 00 & 01 & 01 \\
\hline $\begin{array}{l}\text { Caminhada das } \\
\text { Nascentes }\end{array}$ & 00 & 00 & 00 & 00 & 07 & 07 \\
\hline $\begin{array}{l}\text { Torneio de } \\
\text { Canastra }\end{array}$ & 00 & 00 & 00 & 00 & 02 & 02 \\
\hline Festitália & 00 & 01 & 02 & 01 & 00 & 04 \\
\hline Oktoberfest & 01 & 01 & 01 & 05 & 00 & 08 \\
\hline $\begin{array}{l}\text { Blumenau } \\
\text { Festas e } \\
\text { Eventos }\end{array}$ & 01 & 03 & 02 & 05 & 03 & 14 \\
\hline $\begin{array}{l}\text { Parque Vila } \\
\text { Germânica }\end{array}$ & 08 & 00 & 09 & 11 & 00 & 28 \\
\hline $\begin{array}{l}\text { Secretaria de } \\
\text { Turismo }\end{array}$ & 06 & 13 & 00 & 10 & 05 & 34 \\
\hline TOTAL GERAL & 20 & 25 & 19 & 35 & 18 & 117 \\
\hline
\end{tabular}

A categoria identidade típica foi a mais representativa nos folders da Oktoberfest (5) e Blumenau Festas e Eventos (5). Ela também se destacou no folder do Parque Vila Germânica (11). A categoria gastronomia destacou-se nos folders do Festival da Cerveja (5) e no Parque Vila Germânica (9). A categoria eventos foi a mais citada no folder da Osterdorf (6). Já a categoria lazer foi mais citada no folder da Caminhada das Nascentes (7) e a categoria arquitetura típica destacou-se no folder do Parque Vila Germânica (8). No site da Secretaria de Turismo, as categorias mais representativas foram eventos (13) e identidade típica (10).

A Figura 1 apresenta o diagrama de caminhos criado através da aplicação do tratamento estatístico da Modelagem de Equação Estrutural (MEE). 
Figura 1 - Modelagem de Equação Estrutural (MEE)

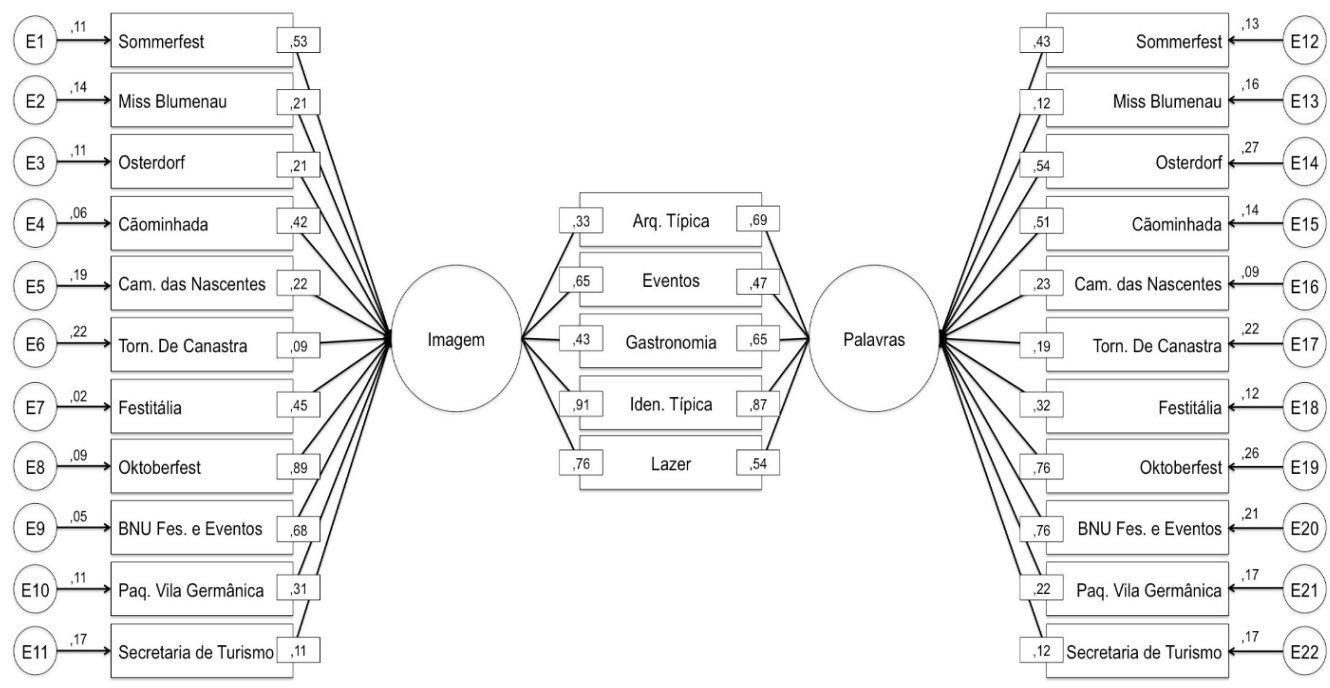

Fonte - Dados da Pesquisa (2015)

A partir da análise da Figura 1, é possível perceber que o evento Oktoberfest apresenta o folder mais representativo da amostra, tanto na análise de imagens (89\%) quanto na análise de palavras (76\%). 0 segundo folder mais representativo, Blumenau Festas e Eventos, aparece logo atrás, com 68\% nas imagens e $76 \%$ nas palavras. Considerando-se apenas as imagens, os materiais menos representativos foram: Torneio de Canastra (9\%) e site da Secretaria de Turismo (11\%) - este último, também é o menos representativo nas palavras, atingindo o percentual de $12 \%$ e empatando com o folder do evento Miss Blumenau. Com relação às dimensões, nota-se que a identidade típica é a que atinge um maior percentual tanto nas imagens (91\%) quanto nas palavras (87\%). Entretanto, por meio da aplicação dos testes de correlação, via Coeficiente de Spearman, não foi possível comprovar a existência de correlação estatística entre as variáveis.

Para identificar a imagem afetiva, foi utilizada a pesquisa realizada por Reis et al. (2015), que, mediante a aplicação da estatística descritiva, identificou a dimensão identidade como a mais representativa da cidade (média de 5,22). Para a maioria dos entrevistados, o município valoriza a sua cultura de origem alemã, algo importante para uma população que demonstra ter orgulho das tradições herdadas de seus antepassados. A maior média geral do estudo $(5,69)$ foi alcançada pela variável "é pela cultura alemã, manifestada através das suas festas e tradições, que Blumenau é reconhecida em todo país", dado que permitiu aos autores constatar que a herança cultural dos colonos alemães fundadores do município constitui-se como elemento fortemente valorizado da identidade local.

Por meio da aplicação da estatística analítica e inferencial, Reis et al. (2015) puderam identificar também outras duas dimensões que exercem forte influência na formação da imagem de Blumenau na ótica de seus residentes: o transporte (77\%) e os serviços governamentais (69\%). As duas dimensões, porém, dizem mais repeito à imagem que os residentes possuem da administração atual do município e não exercem influência na imagem do destino Blumenau como produto turístico. Por fim, os autores concluíram a investigação afirmando que a autoima- 
gem da população representa um elemento-chave para a estratégia de posicionamento turístico do município.

Os resultados alcançados por este estudo corroboram o exposto por Reis et al. (2015), afirmando que, tanto nas palavras quanto nas imagens promocionais de Blumenau, a dimensão identidade típica é a mais representativa. Essa afirmação demonstra que o município está divulgando em suas campanhas publicitárias exatamente a característica mais marcante para seus residentes, a cultura germânica. Em outras palavras, Blumenau conseguiu identificar o seu aspecto diferenciador perante seus concorrentes e, dessa forma, realizar uma divulgação que reflete a realidade do município. Todavia, apesar das evidências, a hipótese de pesquisa $\mathrm{H} 1$ ("existe uma relação positiva entre o material promocional e a autoimagem dos residentes na cidade de Blumenau") não pôde ser comprovada estatisticamente.

É importante notar, porém, que os dados qualitativos não divergiram dos resultados encontrados por outros autores. 0 estudo de Pike e Scott (2009) apontou para a congruência entre a imagem projetada e a identidade do destino. A pesquisa de Karabag, Yavuz e Berggren (2011) verificou que os aspectos culturais exercem influência na promoção do município como marca corporativa. 0 estudo de Tojal (2014) concluiu que as representações estereotipadas dos destinos e de seus habitantes nos materiais promocionais exercem influência no processo de escolha do destino turístico. E também a pesquisa de Stancioiu et al. (2011), realizada na Romênia, identificou os aspectos naturais - imagem identificada por seus habitantes - como marca do destino.

\section{CONSIDERAÇÕES FINAIS}

A realização deste estudo possibilitou o aprofundamento do conhecimento teórico-empírico da temática imagem de destinos mediante revisão bibliográfica detalhada e aplicação prática dos conhecimentos adquiridos na teoria. Com o objetivo de realizar uma análise comparativa entre a imagem cognitiva e a imagem afetiva do destino Blumenau, buscou-se testar a hipótese de pesquisa H1 ("existe uma relação positiva entre o material promocional e a autoimagem dos residentes na cidade de Blumenau").

Depois da coleta e análise das informações, foi possível concluir que Blumenau oferta ao turista o que realmente pode oferecer. Ou, dito de outro modo: há correpondência entre imagem cognitiva e afetiva, e a característica diferenciadora do município - a identidade típica germânica - aparece representada em sua herança cultural, nas tradições transmitidas por seus colonos e em suas festas temáticas.

Todavia, apesar das evidências, a hipótese de pesquisa H1 ("existe uma relação positiva entre o material promocional e a autoimagem dos residentes na cidade de Blumenau") não pôde ser comprovada estatisticamente.

Segundo Reis et al. (2015), a autoimagem da população representa um elemento essencial para a definição da estratégia de posicionamento turístico da marca. Ao se perceberem como parte ativa da cidade, que exerce influência na tomada de decisões do município, os residentes assumem o papel de embaixadores da marca junto aos visitantes, o que contribui significativamente para o desenvolvimento da atividade turística. Os resultados obtidos nesta investigação corroboram o exposto por Reis et al. (2015) reafirmando a importância do posi- 
cionamento estratégico dos destinos turísticos e da identificação de seus aspectos diferenciadores como forma de vantagem competitiva. Nota-se que conseguir identificar o aspecto diferenciador em relação aos concorrentes e, com isso, realizar uma divulgação direcionada a um público-alvo, é uma importante vantagem competitiva, utilizada de forma otimizada pelo destino turístico Blumenau.

Como limitações desta investigação, pode-se citar a utilização de duas fontes diferentes para coleta de dados, uma primária (análise de conteúdo do material promocional da cidade) e outra secundária (estudo de Reis et al.) não concomitantes no tempo (a pesquisa de Reis trabalha com dados coletados em 2015). Também a classificação das palavras e imagens, realizada pelos três autores do estudo, pode ser apontada como limitação. Sugere-se que futuras investigações sejam realizadas utilizando a percepção de um maior número de pessoas com o intuito de aumentar ainda mais a credibilidade das conclusões.

\section{REFERÊNCIAS}

ACERENZA, M. A. Administração do turismo: conceituação e organização. Bauru: Edusc, 2002.

ACHTERKAMP, I.; ROBINSON, T.; MOITAL, M. A imagem da Alemanha como destino de férias: comparação entre britânicos que já visitaram e que ainda não visitaram o país. Turismo Visão e Ação, Balneário Camboriú, v. 13, n. 1, p. 6-19, 2011.

BASAN, L.; BAGARIC, L.; LONCARIC, D. Impact of brand recognition on reinforcing the destination's image. In: INTERNATIONAL SCIENTIFIC CONFERENCE TOURISM IN SOUTHERN AND EASTERN EUROPE, 2., 2013, Opatija. Proceedings... Opatija: ToSEE, 2013. p. 87-100.

BERTOLI, B. J. A imagem de destino da cidade de Blumenau nas redes sociais virtuais de fotografia. 2014. Trabalho de Conclusão de Curso (Graduação em Comunicação Social, Publicidade e Propaganda) - Universidade Regional de Blumenau, Blumenau, 2014.

BLUMENAU. Prefeitura Municipal. Disponível em: <http://www.blumenau.sc.gov.br>. Acesso em: set. 2015.

BLUMENAU. Secretaria de Turismo. Secretaria Municipal de Turismo e Lazer. Blumenau: Secretaria de Turismo, 2015. Disponível em: <http://bit.ly/2nDJM3N >. Acesso em: 30 set. 2015.

BUOSI, M. C. A.; SILVA, A. L. L. A avaliação dos atributos da imagem e sua relação com a imagem global do destino de turismo internacional: Praia de Jericoacoara. Turismo em Análise, São Paulo, v. 24, n. 1, p. 25-40, 2013.

CHAGAS, M. M. Imagem de destinos turísticos: uma discussão teórica da literatura especializada. Turismo Visão e Ação, Balneário Camboriú, v. 10, n. 3, p. 435-455, 2008.

CHAGAS, M.M.; MARQUES JÚNIOR, S. Análise da relação causal entre imagem de destinos, qualidade, satisfação e fidelidade: um estudo de acordo com a percepção do turista nacional no destino turístico Natal. Turismo Visão e Ação, Balneário Camboriú, v. 13, n. 2, p. 274-275, 2011.

DOMENICO, C.; DOMENICO M. Heritage and urban renewal in Dundee: learning from the past when planning for the future of a post-industrial city. Journal of Retail \& Leisure Property, [s. l.], v. 6, n. 4, p. 327-339, 2007.

DONAIRE, J. A.; GALÍ, N. La imagen turística de Barcelona en la comunidad de Flickr. Cuadernos de Turismo, Murcia, n. 27, p. 291-303, 2011. 
GARTNER, W. C. Image formation process. Journal of Travel \& Tourism Marketing, London, v. 2, n. 3, p. 191-216, 1994.

GIACOMINI FILHO, G. A publicidade do turismo no contexto da competitividade. Turismo Visão e Ação, Balneário Camboriú, v. 1, n. 1, p. 61-73, 1998.

JETTER, L. G.; CHEN, R. J. C. Destination branding and images: perceptions and practices from tourism industry professionals. International Journal of Hospitality \& Tourism Administration, London, v. 12, n. 2, p. 174-187, 2011.

KARABAG, S. F.; YAVUZ, M. C.; BERGGREN, C. The impact of festivals on city promotion: a comparative study of Turkish and Swedish festivals. Tourism - An International Interdisciplinary Journal, Zagreb, v. 59, n. 4, p. 447-464, 2011.

LI, X. Examining the "relative image" of tourism destinations: a case study. Current Issues in Tourism, London, v. 15, n. 8, p. 741-757, 2012.

LIMBERGER, P. F.; ANJOS, S. J. G.; PEREIRA, M. L. A efetividade da comunicação em destinos turísticos: um estudo sobre Balneário Camboriú/SC-Brasil. Turydes, Málaga, v. 6, n. 15, p. 1-14, 2013.

LUBOWIECKI-VIKUK, A. P.; BASINSKA-ZYCH, A. Sport and tourism as elements of place branding a case study on Poland. Journal of Tourism Challenges and Trends, [s. l.], v. 4, n. 2, p. 33-52, 2011.

LYU, X.; XU, H.; LIN, S. Brand Hijack: the alienated evolution process of destination image. Tourism Tribune, Beijing, v. 29, n. 6, p. 67-75, 2014.

MENDES, J.; VALLE, P. O.; GUERREIRO, M. Destination image and events: a structural model for the Algarve case. Journal of Hospitality Marketing \& Management, London, v. 20, n. 3-4, p. 366-384, 2011.

MERRILEES, B.; MILLER, D.; HERINGTON, C. Antecedents of residents' city brand attitudes. Journal of Business Research, Amsterdam, v. 62, n. 3, p. 362-367, 2008.

PEREIRA, M. L. Avaliação da imagem do destino turístico: fatores pessoais e estímulos na perspectiva do turista de Porto Belo (SC), Brasil. 2013. Dissertação (Mestrado em Turismo e Hotelaria) - Universidade do Vale do Itajaí, Balneário Camboriú, 2013.

PÉREZ-NEBRA, A. R.; TORRES, C. VOL. Imagem do Brasil como país de destino turístico: uma pesquisa da psicologia do consumidor. Turismo Visão e Ação, Balneário Camboriú, v. 4, n. 10, p. 101-114, 2002.

PIKE, S. Destination image literature: 2001 to 2007. Acta Turistica, Zagreb, v. 19, n. 2, p. 107-125, 2007.

PIKE, S.; SCOTT, N. Destination brand equity among the host community: a potential source of competitive advantage for DMOS. Acta Turistica, Zagreb, v. 21, n. 2, p. 160-183, 2009.

REIS, C. et al. City branding: the attributes of Blumenau/SC (Brazil) city and the implications for the tourism development. In: INTERNATIONAL MARKETING TRENDS CONFERENCE, 14., 2015, Paris. Proceedings... Paris: International Marketing Trends Conference, 2015. Disponível em: <http://bit.ly/2mmegaz>. Acesso em: 20 mar. 2017.

STANCIOIU, A. F. et al. The image of the tourism destination: a supporting element in the development of the regional tourism brand study case: Muntenia. Theoretical and Applied Economics, Bucharest, v. 18, n. 2, p. 139-152, 2011.

STYLOS, N.; ANDRONIKIDIS, A. Exploring the cognitive image of a tourism destination. Tourismos: An International Multidisciplinary Journal of Tourism, Chios, v. 8, n. 3, p. 77-97, 2013.

TOJAL, M. D. A importância dos folhetos e brochuras na construção da imagem de um destino turístico: estudo comparativo de três casos: Vila do Conde, Póvoa de Varzim e 
Esposende. Pasos: Revista de Turismo y Patrimonio Cultural, Tenerife, v. 12, n. 2, p. 369382, 2014.

UPADHYAYA, M. Influence of destination image and destination personality: an empirical analysis. Journal of Marketing \& Communication, New Delhi, v. 7, n. 3, p. 40-47, 2012.

WANG, J. C.; LI, T. Y. Evaluation on tourist destination brand logos: taking China excellent tourism cities as examples. Tourism Tribune, Beijing, v. 27, n. 2, p. 43-51, 2012.

$\mathrm{XU}$, F. et al. System building of regional urban tourism brands based on niche theory: case study of the Shandong provincial capital metropolitan area. Tourism Tribune, Beijing, v. 28, n. 9, p. 43-52, 2013.

ZHOU, Y.; SU, L. Intangible heritage's authenticity in cultural practices: reproduced Jingshanchayan. Tourism Tribune, Beijing, v. 29, n. 7, p. 23-30, 2014.

Recebido em: 04/07/2016

Aprovado em: 13/03/2017 